\title{
BMJ Open Trends and changes in paediatric tonsil surgery in Sweden 1987-2013: a population-based cohort study
}

\author{
Anna Borgström, ${ }^{1,2}$ Pia Nerfeldt, ${ }^{1,2}$ Danielle Friberg, ${ }^{1,2}$ Ola Sunnergren, ${ }^{3}$ \\ Joacim Stalfors ${ }^{4}$
}

To cite: Borgström A, Nerfeldt P, Friberg D, et al. Trends and changes in paediatric tonsil surgery in Sweden 1987-2013: a population-based cohort study. BMJ Open 2017;7: e013346. doi:10.1136/ bmjopen-2016-013346

- Prepublication history for this paper is available online. To view these files please visit the journal online (http://dx.doi.org/10.1136/ bmjopen-2016-013346).

Received 7 July 2016 Revised 14 November 2016 Accepted 6 December 2016

\section{CrossMark}

\section{${ }^{1}$ Department of Otorhinolaryngology, Karolinska University Hospital, Stockholm, Sweden ${ }^{2}$ Department of Clinical Science, Intervention and Technology, CLINTEC, Karolinska Institute, Stockholm Sweden ${ }^{3}$ Department of Otorhinolaryngology, Ryhov County Hospital, Jönköping, Sweden \\ ${ }^{4}$ Institute of Clinical Sciences, Sahlgrenska Academy at the University of Gothenburg, Gothenburg, Sweden}

Correspondence to Dr Anna Borgström; anna. borgstrom@karolinska.se

\section{ABSTRACT}

Objectives: The objective of this study was to longitudinally describe the history of tonsil surgery in Swedish children and adolescents regarding incidence, indications for surgery, surgical methods and the age and gender distributions.

Setting: A retrospective longitudinal population-based cohort study based on register data from the Swedish National Patient Register (NPR) and population data from Statistics Sweden.

Participants: All Swedish children $1-<18$ years registered in the NPR with a tonsil surgery procedure 1987-2013.

Results: 167894 tonsil surgeries were registered in the NPR 1987-2013. An increase in the total incidence rate was observed, from 22/10 000 person years in 1987 to $47 / 10000$ in 2013. The most marked increase was noted in children $1-3$ years of age, increasing from 17 to $73 / 10000$ person years over the period. The proportion children with obstructive/sleep disordered breathing (SDB) indications increased from $42.4 \%$ in 1987 to $73.6 \%$ in 2013. Partial tonsillectomy, tonsillotomy (TT), increased since 1996 and in 2013 $55.1 \%$ of all tonsil procedures were TTs.

Conclusions: There have been considerable changes in clinical practice for tonsil surgery in Swedish children over the past few decades. Overall, a doubling in the total incidence rate was observed. This increase consisted mainly of an increase in surgical procedures due to obstructive/SDB indications, particularly among the youngest age group (1-3 years old). TT has gradually replaced tonsillectomy as the predominant method for tonsil surgery.

\section{INTRODUCTION}

Tonsil surgery has an ancient history and was first described in the literature almost 3000 years ago. ${ }^{1}$ Today, tonsillectomy (TE), with or without adenoidectomy, is one of the most frequently performed surgical procedures in children, with over 530000 TEs performed on children in the USA each year ${ }^{2}$ and nearly 9000 tonsil procedures performed on children in Sweden in $2013 .^{3}$

\section{Strengths and limitations of this study}

- This study describes the epidemiological trends of tonsil surgery in Swedish children over the past few decades.

- The major strengths of the study are the large population size and the use of the Swedish National Patient Register (NPR) with unique nationwide data and high coverage.

- The study covers a long period of time and can therefore be used to determine actual longitudinal application of clinical practice concerning tonsil surgery in Sweden.

- One limitation is the potential inherent weakness of the NPR with the possibilities of missing values and inaccurate data reporting.

- Data are limited to a Swedish population and the generalisability from a global perspective might be somewhat limited, but the results can possibly indicate the evolutionary factors affecting tonsil surgery on a more global scale.

Over the past 100 years, tonsil surgery has undergone a number of changes, particularly with respect to indications and surgical methods. Prior to 1900, the predominant surgical technique was tonsillotomy (TT) with subtotal intracapsular removal of the tonsils. ${ }^{4}$ Then, along with advances in anaesthesiology at the beginning of the twentieth century, total extracapsular TE gradually became more common. This paradigm shift from TT to TE was essentially complete by $1950^{4}$ and during the second half of the twentieth century, TE was the prevailing method. Later, in the 1990s, the previously abandoned method of TT was revived in some countries, including Sweden and Austria. ${ }^{5}$ Compared with TE, TT is associated with fewer perioperative morbidities, such as postoperative haemorrhage and pain, ${ }^{6} 7$ and it is now primarily used to treat sleep disordered breathing (SDB) caused by upper airway obstruction due to tonsil hypertrophy. ${ }^{8}$ 
Along with shifts in surgical methods, the indications for tonsil surgery have also changed considerably. At the beginning of the twentieth century, in the preantibiotic era, infection or recurrent tonsillitis was the main indication for tonsil surgery. ${ }^{9}$ Following the introduction of antibiotics in the 1950s, the number of TEs decreased dramatically over the following decades. ${ }^{10}{ }^{11}$ Then, in the 1970s the first cases of paediatric obstructive sleep apnoea (OSA) were identified ${ }^{12}$ and a successive shift in indications followed. Today, upper airway obstruction/ SDB is the most common indication for tonsil surgery in children, having surpassed the second largest indication group, infections related tonsil disease. ${ }^{9}$

A more detailed analysis of the trends and changes in paediatric tonsil surgery during the twentieth century is difficult to perform due to lack of high-quality data sources.

The National Board of Health and Welfare in Sweden has initiated a national registry, known as the Swedish National Patient Register (NPR), with the aim of collecting data on all healthcare procedures performed in Sweden. ${ }^{13}$ The NPR provides the possibility of performing detailed analyses of trends and changes in healthcare practices in a nationwide population. Indeed, this database provides a unique source of data with few, if any, equals around the world.

The importance of monitoring historical and current trends in medical practice cannot be overstated. Some of the most important changes in indications and methods for paediatric tonsil surgery over the last century were not the result of evidence-based research; rather they were based on local praxis and traditions. Furthermore, the related consequences of these changes regarding outcome, complications and economic costs are often unstudied.

The objective of this study was to longitudinally describe the history of tonsil surgery in Swedish children and adolescents with respect to incidence, indications for surgery and surgical methods, as well as age and gender distributions. A description of the trends in paediatric tonsil surgery is a prerequisite to identifying critical research areas that will allow us to determine best practices and improve healthcare quality and can also be a guide to future public health planning.

\section{MATERIALS AND METHODS}

\section{Study design}

A retrospective longitudinal population-based cohort study based on register data from the NPR and population data from Statistics Sweden.

\section{Data sources}

\section{Swedish National Patient Register}

All medical data were collected from the NPR. Registration in the NPR is mandatory by law for public and private care providers (except primary care) in Sweden. The NPR contains information regarding medical data (diagnoses, surgical procedures), patient- related data (gender, age, personal identity number) and information regarding healthcare providers. The NPR is thought to have complete national coverage for inpatient care starting in $1987^{14}$; outpatient care was included beginning in 1997 and was mandatory starting in 2001 .

\section{Statistics Sweden}

A government agency that coordinates the official statistics of Sweden and provides statistical information on the Swedish population. ${ }^{15}$

\section{Study population}

The study population included all patients $1-<18$ years registered in the NPR with a tonsil surgery procedure between 1 January 1987 and 31 December 2013. The search was based on surgical codes in the Nordic Medico-Statistical Committees Classification of Surgical Procedures, including TE and TT with or without simultaneous adenoidectomy.

Diagnosis codes from the International Classification of Diseases (ICD) were collected from the NPR. Since 1987, two different ICD classifications have been used (ICD-9 1987-1996 and ICD-10 1997-). For patients registered from 1997 (ICD-10) onward, it was possible to exclude patients with malignant disease (C- or D 0-48 codes).

Population statistics for all individuals in Sweden aged $1-<18$ years during the study period were collected from the Sweden Statistics population database.

Indications for surgery were categorised in two main groups: 'obstructive/SDB' and 'infectious' (table 1); all other indications were referred to as 'other'. The indication groups were analysed with respect to age, gender and longitudinal incidence.

\section{Statistical analysis}

Mainly descriptive statistics were used. The denominator used for incidence rate calculations was the sum of the end-of-year population estimates for each year and age.

For comparison of the event rate between boys and girls, assuming that the events are Poisson distributed, an exact binomial test was performed.

Gender differences regarding indication for surgery in specific age groups were tested using the CochranMantel-Haenszel test.

Incidence rate trends were tested by using joinpoint regression models (Joinpoint Regression program, V.4.3.1.0, April 2016; Statistical Methodology and Applications Branch, Surveillance Research Program, National Cancer Institute) that identified points (joinpoints) where linear trends of tonsil surgery changed significantly in direction or magnitude. The rate of change for each trend was tested to determine whether the change was significantly different from zero. In the final model, each trend is described by an annual percentage change (APC) with a 95\% CI. The joinpoint analyses were performed for boys and girls separately.

All significance tests were two-sided and conducted at the $5 \%$ significance level. All analyses except the 
Table 1 Patients were categorised into 'obstructive/SDB' and 'infectious' groups based on the diagnoses from the ICD-9 and ICD-10 classification

Obstructive/SDB
ICD-9 (1987-1996)
307E Specific Sleep Disturbances
474B Hypertrophy of adenoids and tonsils
474C Adenoid vegetations
519W Other specified diseases of the respiratory system not
classified
780F Sleep disturbances
786A Dyspnea and respiratory abnormalities
786B Stridor
519W Other specified diseases of the respiratory system not
elsewhere classified

\section{ICD-10 (1997-)}

G47.0 Insomnia

G47.2 Disorders of the sleep-wake schedule

G47.3 Sleep apnoea

G47.30 Sleep apnoea, unspecified

G47.39 Sleep apnoea, other

G47.8 Other sleep disorders

G47.9 Sleep disorder, unspecified

J35. 1 Hypertrophy of tonsils

J35.2 Hypertrophy of adenoids

J35.3 Hypertrophy of tonsils with hypertrophy of adenoids

R06.1 Stridor

R06.3 Periodic breathing

R06.5 Mouth breathing

R06.50 Mouth breathing and snoring

R06.8 Other and unspecified abnormalities of breathing

Infectious
ICD-9 (1987-1996)
101X Vincent's angina
469X Acute nasopharyngitis
462X Acute pharyngitis
463X Acute tonsillitis
465A Acute laryngopharyngitis
465X Acute upper respiratory infection of
unspecified site
472 Chronic pharyngitis and nasopharyngitis
472B Chronic pharyngitis
472C Chronic nasopharyngitis
474A Chronic tonsillitis
475X Peritonsillar abscess
682B Cellulitis/abscess, neck
101X Vincent's angina
ICD-10 (1997-)
A42.2 Cervicofacial actinomycosis
A42.8 Other forms of actinomycosis
A42.9 Actinomycosis, unspecified
A69.1 Other Vincent infections
B27.0 Mononucleosis due to Epstein-Barr virus
B27.1 Cytomegaloviral mononucleosis
B27.8 Other infectious mononucleosis
B27.9 Infectious mononucleosis, unspecified
J00.9 Acute nasopharyngitis
J02.0 Streptococcal pharyngitis
J02- Acute pharyngitis
J02.9 Acute pharyngitis, unspecified
J03.0 Streptococcal tonsillitis
J03.8 Acute tonsillitis due to other specified
organisms
J03.9 Acute tonsillitis, unspecified
J06.9 Acute upper respiratory infection,
unspecified
J31.1 Chronic nasopharyngitis
J31.2 Chronic pharyngitis
J35.0 Chronic tonsillitis
J35.00 Chronic tonsillitis
J35.09 Chronic tonsillitis

ICD, International Classification of Diseases; SDB, sleep disordered breathing

Joinpoint regression were performed with SAS System V.9 (SAS Inst., Cary, North Carolina, USA).

\section{RESULTS}

In total, 167894 tonsil surgeries (82 398 (49\%) girls and $85496(51 \%)$ boys) were registered in the NPR between 1987 and 2013 (table 2).

\section{Incidence}

The overall incidence rate of registered tonsil operations in patients aged $1-<18$ years increased from $22 / 10000$ person years in 1987 to $47 / 10000$ person years in 2013 (figure 1). This increase was continuous over the study period, with the exception from 1996 to 2001, when a decrease was observed (figure 1).
The most marked increase in incidence was noted in children aged 1-3 years, increasing from 17/10 000 person years in 1987 to $73 / 10000$ person years in 2013 . This 1-3-year-old group increased their share of total tonsil surgeries from $13.5 \% 1987$ to $29.4 \%$ in 2013 . The trends in incidence rates for boys and girls are shown in figure 2A, B. Trends were similar and significant for both genders (table 3 ).

\section{Gender and age}

For the total time period, the incidence difference between the genders were significant $(p=0.0011$, exact binomial test), showing a dominance of boys (table 2). 
Table 2 The number and incidence rate of tonsil surgery procedures registered in the NPR between 1987 and 2013 by age, gender ( $\mathrm{F}=$ females, $\mathrm{M}=$ males) and time period

\begin{tabular}{|c|c|c|c|c|c|c|c|c|c|c|c|c|c|c|c|}
\hline \multirow[b]{2}{*}{ Age group } & \multicolumn{2}{|c|}{$1987-1990$} & \multicolumn{2}{|c|}{ 1991-1994 } & \multicolumn{2}{|c|}{ 1995-1998 } & \multicolumn{2}{|c|}{ 1999-2002 } & \multicolumn{2}{|c|}{ 2003-2006 } & \multicolumn{2}{|c|}{ 2007-2010 } & \multicolumn{2}{|c|}{ 2011-2013 } & \multirow{2}{*}{$\begin{array}{l}\text { 1987-2013 } \\
n\end{array}$} \\
\hline & $\mathbf{n}$ & Rate & $\mathbf{n}$ & Rate & $\mathrm{n}$ & Rate & $\mathbf{n}$ & Rate & $\mathrm{n}$ & Rate & $\mathbf{n}$ & Rate & $\mathbf{n}$ & Rate & \\
\hline F1-3 & 1003 & 16 & 2236 & 31 & 2073 & 33 & 1475 & 28 & 1834 & 32 & 2660 & 42 & 2838 & 56 & \\
\hline F 4-6 & 2054 & 36 & 3938 & 60 & 4443 & 62 & 2801 & 47 & 2959 & 54 & 3881 & 64 & 3800 & 78 & \\
\hline F 7-9 & 1375 & 24 & 1937 & 33 & 2341 & 34 & 1671 & 24 & 1353 & 24 & 1700 & 30 & 1568 & 33 & \\
\hline F 10-12 & 1146 & 20 & 1448 & 25 & 1497 & 24 & 1208 & 17 & 1153 & 17 & 1108 & 19 & 1032 & 23 & \\
\hline F 13-15 & 1682 & 27 & 1702 & 29 & 1639 & 28 & 1543 & 24 & 1771 & 24 & 1876 & 28 & 1090 & 25 & \\
\hline F 16-17 & 1687 & 38 & 1621 & 40 & 1481 & 38 & 1535 & 38 & 2153 & 46 & 2592 & 52 & 1494 & 47 & \\
\hline F subtotal & 8947 & 26 & 12882 & 37 & 13474 & 37 & 10233 & 28 & 11223 & 31 & 13817 & 39 & 11822 & 45 & 82398 \\
\hline M 1-3 & 1677 & 26 & 3509 & 47 & 3235 & 49 & 2416 & 43 & 2861 & 47 & 4140 & 62 & 4370 & 82 & \\
\hline M 4-6 & 2934 & 49 & 5278 & 76 & 5979 & 79 & 3793 & 61 & 4017 & 70 & 5549 & 87 & 5051 & 97 & \\
\hline M 7-9 & 1503 & 25 & 2117 & 34 & 2447 & 34 & 1724 & 23 & 1496 & 25 & 1808 & 30 & 1693 & 34 & \\
\hline M 10-12 & 790 & 13 & 1081 & 18 & 1008 & 15 & 847 & 11 & 851 & 12 & 863 & 14 & 805 & 17 & \\
\hline M 13-15 & 746 & 11 & 898 & 15 & 866 & 14 & 730 & 11 & 805 & 10 & 1006 & 15 & 630 & 14 & \\
\hline M 16-17 & 766 & 17 & 769 & 18 & 672 & 16 & 768 & 18 & 1038 & 21 & 1235 & 24 & 725 & 21 & \\
\hline M subtotal & 8416 & 24 & 13652 & 37 & 14207 & 37 & 10278 & 27 & 11068 & 29 & 14601 & 39 & 13274 & 47 & 85496 \\
\hline $\begin{array}{l}\text { Total } \\
\text { p Value }\end{array}$ & 17363 & 25 & 26534 & 37 & 27681 & 37 & 20511 & 28 & 22291 & 30 & 28418 & 39 & 25096 & 46 & $\begin{array}{l}167894 \\
0.0011\end{array}$ \\
\hline
\end{tabular}

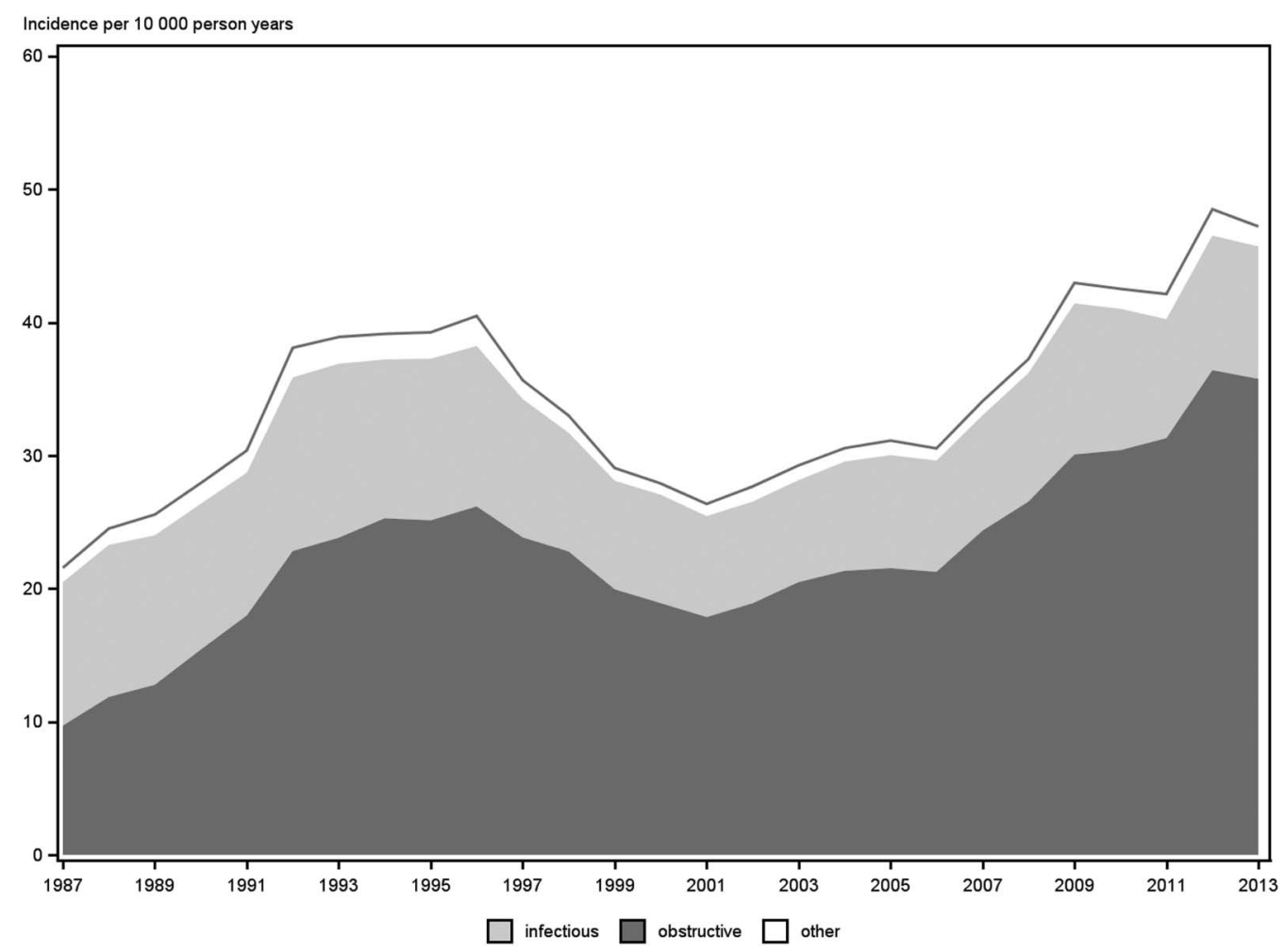

Figure 1 The incidence and indications of tonsil surgery in children aged $1-<18$ years from 1987 to 2013. Incidence/100 000 person years.

Figure 3A, B shows the age and gender distributions as well as the indication groups. For both genders, the indication 'obstructive/SDB' was most common in the younger age groups, with a peak between ages 2 and 6 , and the highest incidence (113/10 000 person years) was in 3-year-old boys with obstruction between 2008 and 2013 (figure 3A, B). Infectious indications were more common in teenagers for both genders, particularly for girls, whose incidence was three to four times greater compared with boys of the same age. 
A

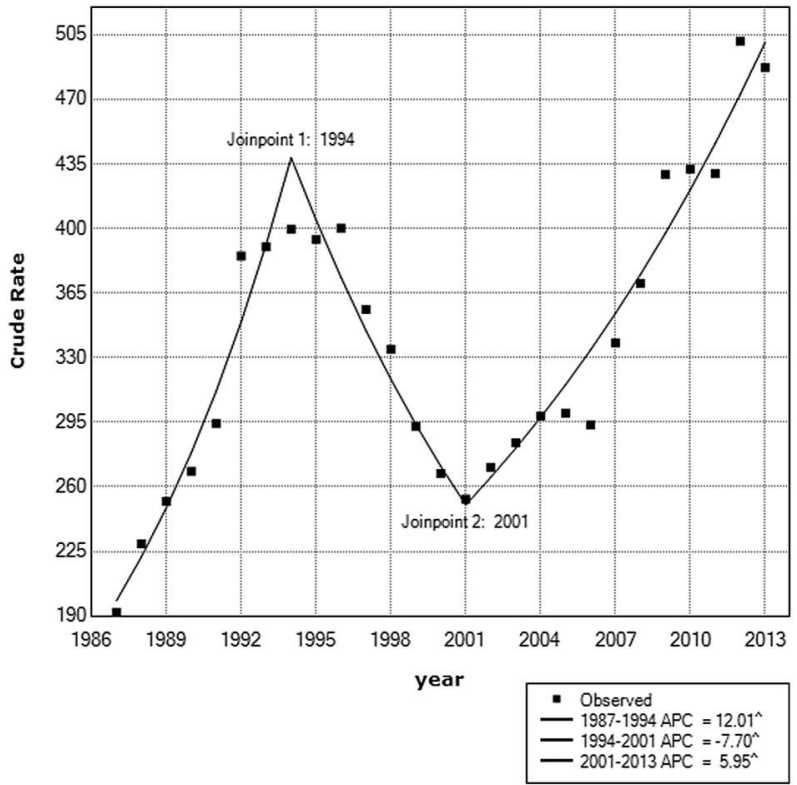

B

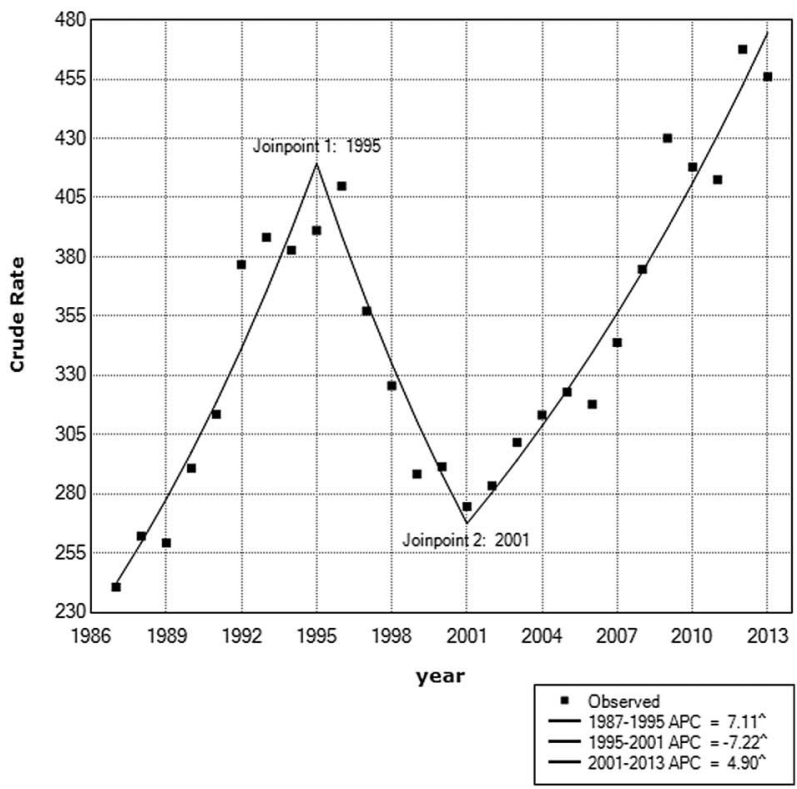

Figure 2 ( $A$ and $B$ ) Joinpoint regression analyses showing the trends in the incidence rate of tonsil surgery for boys $(A)$ and girls (B) 1987-2013. For both genders, two joinpoints were observed (1994 and 2001 for boys, 1995 and 2001 for girls). The crude rate is the incidence rate/100 000 person years. APC, annual percentage change.

The gender differences were significant in the age group 2-6-year-olds who were operated for obstructive/ SDB indications with a male dominance $(\mathrm{p}<0.001)$ as well as in the age group 14-17-year-olds operated for infection with a female dominance $(p<0.001$, CochranMantel-Haenszel test).

Further, figure 3A, B shows that the highest incidence levels for tonsil surgery for boys and girls at all ages were observed over the previous time period, 2008-2013. The major reason for this increase was operations in young children with obstruction.

\section{Indications}

The indications for surgery between 1987 and 2013 are presented as proportions of the total incidence in figure 1. The incidence of tonsil procedures performed for the indication obstructive/SDB increased nearly fourfold over this period, from 10 to 36/10 000 person years (figure 1). Since 1990, obstruction/SDB constituted the major indication group. In 1987, $42.4 \%$ of tonsil procedures were performed for obstructive/SDB, whereas in 2013, this proportion was $73.6 \%$. In the youngest age groups (children $1-<4$ years old), the vast majority $(>90 \%)$ of tonsil procedures were performed for obstructive/SDB indications. The incidence of infectious tonsil disease as an indication remained stable over the study period.

\section{SURGICAL METHODS}

Figure 4 shows the proportions of TE and TT $( \pm$ adenoidectomy) between 1987 and 2013. An increase in the number of TT procedures began in 1996 with a gradual annual increasing trend, followed by a sharp increase from 2006 onward. From 1997 to 2005, TT increased from $1.8 \%$ to $9.8 \%$ of all tonsil procedures, and from 2006 to 2013 it increased from $11.2 \%$ to $55.1 \%$ of all procedures. From 2011 onwards, TT was more common than TE. The major indication for TT was obstruction, and in $2013>96 \%$ of all TTs were performed for this indication. When TE was used, about half (49\%) of the procedures were performed due to infection in 2013, a percentage that was generally stable during the observed period.

In the youngest group (1-3-year-olds), TT was most common, and in $2013,71 \%$ of all tonsil surgeries in this age group were TTs.

\section{DISCUSSION}

This study was based on a national cohort and describes the epidemiological trends during 1987-2013 for tonsil surgeries in Swedish children. Overall, the incidence rate for paediatric tonsil surgery has roughly doubled during the observation period due to an increase in the number of procedures performed for the obstruction/ SDB indication. Furthermore, TT has gradually replaced TE as the predominant surgical method. Few previous studies have addressed these topics in large national cohorts over long periods of time.

\section{Incidence}

During the study period, 1987-2013, there was a near doubling of the incidence rate for tonsil operations in Swedish children, with incidence rates reaching 47/ 10000 person years in 2013. A similar, albeit weaker, trend was reported in a Danish study based on a national cohort, where the cumulative risk of $\mathrm{TE}$ in the 
Table 3 Summary of joinpoint APC for tonsil surgery incidence in boys (A) and girls (B) 1987-2013

\begin{tabular}{|c|c|c|c|c|c|}
\hline Lower end point & Upper end point & APC & Lower $95 \% \mathrm{Cl}$ & Upper $95 \% \mathrm{CI}$ & p Value \\
\hline \multicolumn{6}{|l|}{ (A) Boys } \\
\hline 1987 & 1994 & 12.0 & 9.3 & 14.8 & $<0.001$ \\
\hline 1994 & 2001 & -7.7 & -10.2 & -5.1 & $<0.001$ \\
\hline 2001 & 2013 & 6.0 & 5.0 & 6.9 & $<0.001$ \\
\hline \multicolumn{6}{|l|}{ (B) Girls } \\
\hline 1987 & 1995 & 7.1 & 5.3 & 8.9 & $<0.001$ \\
\hline 1995 & 2001 & -7.2 & -10.2 & -4.2 & $<0.001$ \\
\hline 2001 & 2013 & 4.9 & 4.0 & 5.8 & $>0.001$ \\
\hline
\end{tabular}

first 20 years of life increased nearly 20\% between 1980 and 2001. ${ }^{16}$

Another important observation in the present study was that the incidence for the youngest group of children, 1-3 years of age, increased more than fourfold over the study period. This trend was also seen in a study from the UK in which TE rates among children $<4$ years of age increased from 13.5 to $21.3 / 10000$ children during the period from 2001 to 2012 . $^{17}$

The Swedish incidence rate can be viewed as relatively low compared with other nations. Van den Akker et al reported large differences in $\mathrm{TE}$ rates between several European countries, the US, Canada and Australia. Incidence rates varied from 19/10 000 person years in Canada to $118 / 10000$ in Northern Ireland. ${ }^{18}$ The incidence rates in our study varied from 22/10 000 person years in 1987 to $47 / 10000$ in 2013. Potential explanations to this variation in incidence rates between different countries include differences in national guidelines for tonsil surgery, differences in the availability of medical service and differences in reimbursement systems.

For instance, in the Netherlands, antibiotics are not recommended for uncomplicated tonsillitis, which could be a reason for the relatively higher incidence of $\mathrm{TE}$ in that country. ${ }^{19}$ In contrast, in the NHS system of the UK, the incidence rate has decreased after evidence regarding outcomes following tonsil surgery for infectious indications were questioned. Concomitant with this decrease in $\mathrm{TE}$ rates, there was an increase in admissions and serious complications due to tonsil infections. ${ }^{20}$

Interestingly, local geographic and sociodemographic factors have been reported to influence tonsil surgery incidence rates. ${ }^{1721}$ A recent Swedish study reported an increased risk of paediatric SDB in families with low socioeconomic status, ${ }^{22}$ and this has also been suggested to be a risk factor for group A streptococcal infections. ${ }^{23}$

\section{Age and gender}

We observed a peak in incidence rates during the preschool years, the same age that the prevalence of SDB/ OSA peaks. ${ }^{24}$ This peak was significantly higher for boys than it was for girls, which is likely because childhood
SDB is more common in boys. ${ }^{25}$ Another peak occurred in teenage girls with primarily infectious indications. This significant difference in gender distributions among teenagers could indicate that infectious tonsil diseases are more prevalent in females, although the reasons for this are not fully understood. Overall the observed age and gender distributions were well in line with previous publications showing similar results. ${ }^{21} 26$

\section{Indications}

Overall, a shift in the prevalence of indications was observed, with obstructive/SDB indications increasing over the study period. Obstruction/SDB now constitutes the primary indication for tonsil surgery in children, which is consistent with other published studies. ${ }^{27} 28$ The incidence for infectious indications remained relatively stable over the study period.

The most common indication in the younger age group by far was obstruction/SDB, which was seen in this study as well as in several previous studies, ${ }^{10} 28$ likely reflecting an increased awareness of upper airway obstruction and SDB as a common disease in the paediatric population. In a single county study from Minnesota, a comparable large-scale shift in indications was observed with an increase in the percentage of SDB/obstructive indications from $12 \%$ in 1970 to $77 \%$ in $2005 .^{26}$ Bhattacharyya and $\operatorname{Lin}^{29}$ reported that the rates of paediatric adenotonsillectomy nearly doubled between 1996 and 2006, likely due to increased recognition of SDB and OSA. An increasing use of polysomnography (PSG) could have supported this theory of increased awareness of obstructive/SDB indications, but no such data were available in our database for this cohort. Overall, PSG is very sparsely used in children in Sweden.

Another possible explanation to the increase in obstructive/SDB indications could be increasing prevalence of obesity. However, studies of obesity among Swedish children have observed an increase from 1984 to 2000 , but thereafter a stabilisation of the prevalence. $^{30-32}$ In our database, no information about obesity was available and therefore this could not be further analysed. 


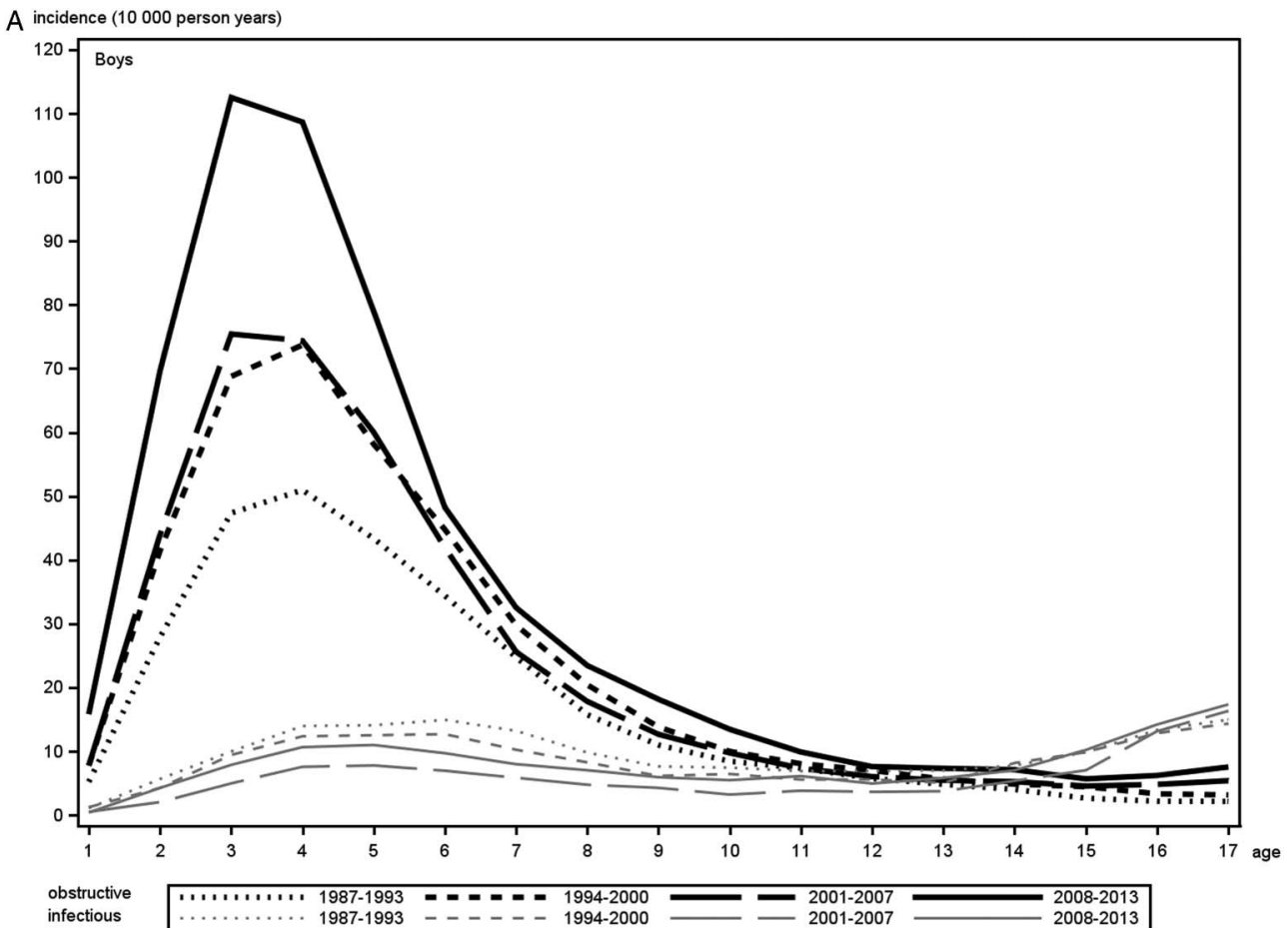

$B$ incidence (10 000 person years)

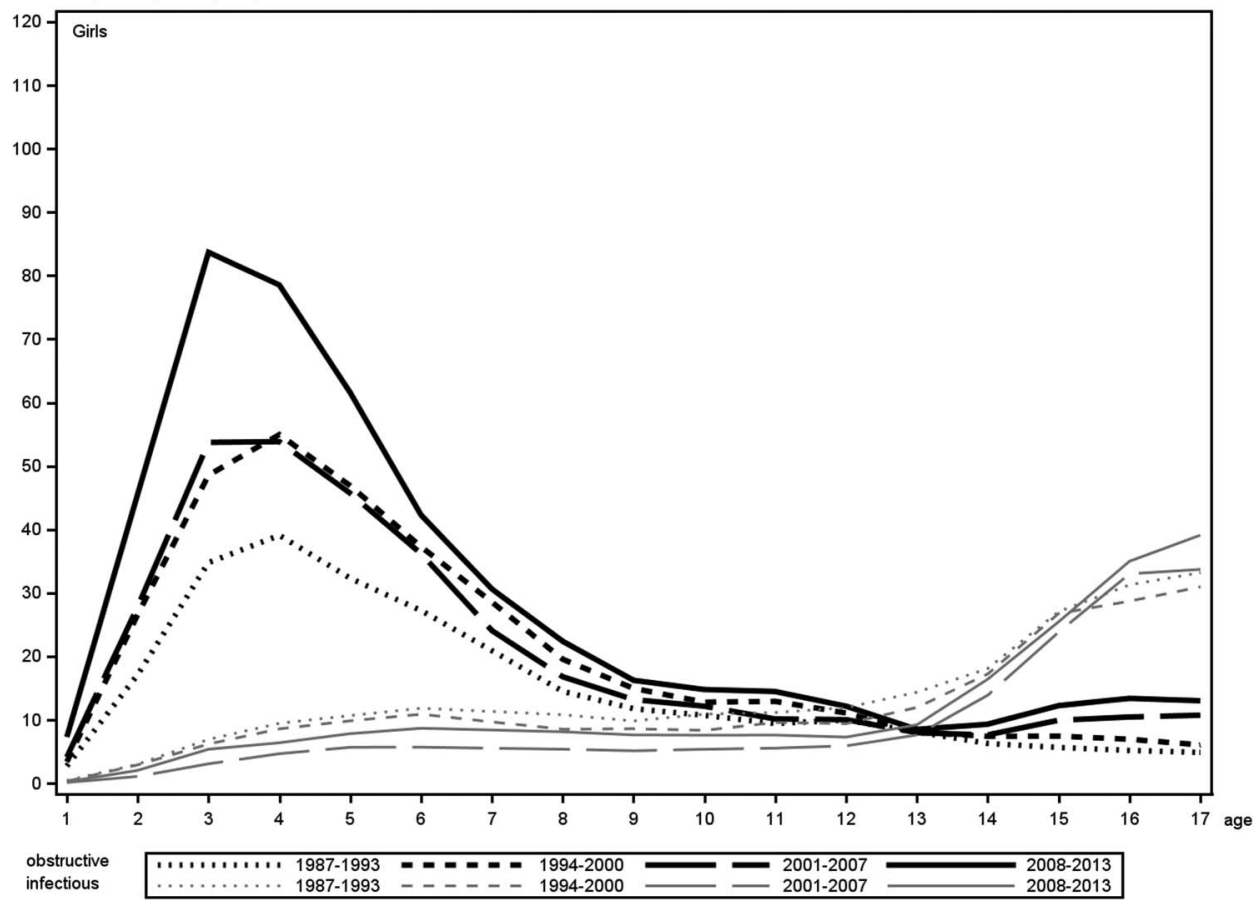

Figure 3 ( $A$ and B) Incidence of tonsil surgery procedures for boys (A) and girls (B) aged 1-<18 years between 1987 and 2013 separated by age and indication. Black lines represent obstructive indications and grey lines represent infectious. Each curve represents a 6-year or 7-year period.

\section{Surgical methods}

Along with a shift in indications, there has also been a shift in surgical methods, with TT gradually replacing $\mathrm{TE}$ as the most common surgical method for children in Sweden. This was also the conclusion of a study based on data from another Swedish registry independent of the NPR, the National Tonsil Register in Sweden. ${ }^{33}$ Since 2011, TT has become more common than TE in Sweden. That same year, new national guidelines for TT were issued in Sweden. ${ }^{34}$ One possible explanation for our findings could be that Swedish ENT surgeons consider TT to be safe enough to perform on small 
$\%$

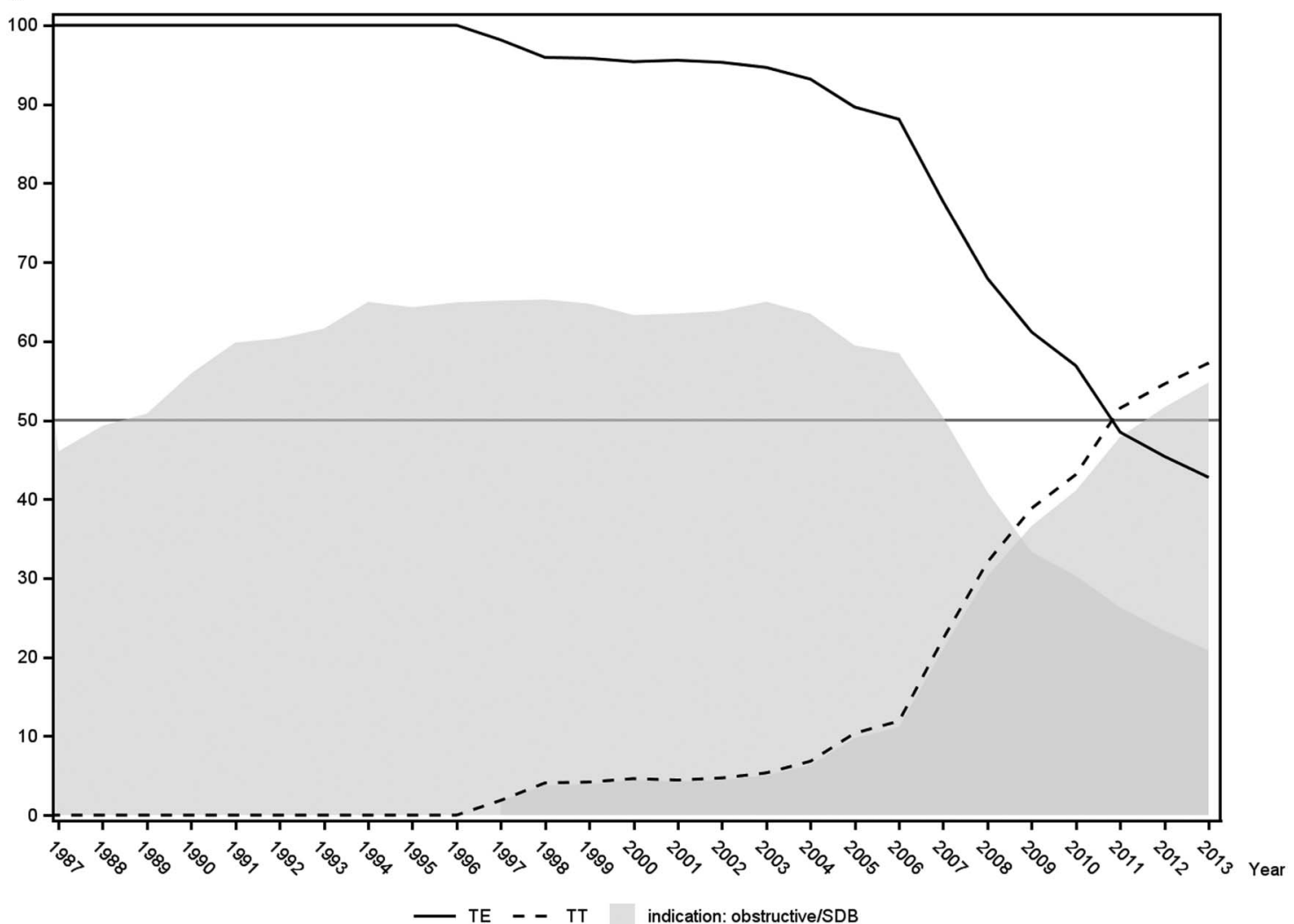

Figure 4 Distributions of the percentage of TE and TT procedures, with or without simultaneous adenoidectomy, performed between 1987 and 2013. The proportion due to an obstructive/SDB indication is shadowed for each method. TE, tonsillectomy. TT, tonsillectomy.

children. TT has advantages over TE with respect to postoperative complications such as pain and bleeding $^{6} 35$ with comparable outcomes for symptom relief. ${ }^{36}$ A known disadvantage of TT is the regrowth of tonsils with recurrence of obstructive/SDB symptoms and need for reoperation. A recent Swedish study based on the NPR found a seven times higher risk for reoperation after TT than after TE, with the highest risk in the youngest age groups. ${ }^{37}$

However, the clinical practice of TT for treating airway obstructions in children seem to be spreading; for instance, in Austria, several serious complications with post-tonsillectomy haemorrhage has led to a switch to TT. $^{5}$

\section{Strengths and limitations}

In this study, there was a marked decrease in the incidence rate of tonsil surgeries between 1996 and 2001. The reasons for this decrease in the number of recorded surgeries were analysed together with the representatives from the NPR (Personal communication with Quality Manager for the Patient Register, Anders Jacobsson). One reason for this dip could be a failure on the part of the NPR to collect data on performed surgeries, perhaps due to the increased use of day-care surgery between 1997 and 2001. Another reason could be insufficient reporting to the NPR from private hospitals, which became more numerous during this period. However, we believe this decrease was too great to be explained by failed registrations alone and must represent an actual decrease in the number of surgeries, although the true extent of this decrease cannot be precisely determined.

The NPR is generally considered to have high coverage, ${ }^{14}$ although like all clinical registers, it has potential inherent limitations, including inaccurate data reporting and missing values.

Major strengths include the large population size of the register and its wealth of unique nationwide data over a long time period. It can therefore be used to determine actual longitudinal application of a clinical practice in a specific country over long periods of time.

\section{CONCLUSIONS}

Our results showed considerable changes in clinical practices for tonsil surgery in Sweden during the period 1987 to 2013. Overall, a doubling in the incidence rates was observed during this period. The reason for this change was an increase in surgical procedures due to upper airway obstruction/SDB, particularly among the youngest age group (1-3 years old) and among boys. Further, TT has gradually replaced TE as the predominant surgical method for obstructive/SDB indications. 
The incidence rates for infectious indications for tonsil surgery have remained relatively stable during the study period, and the most common patients in the infectious group were teenage girls.

Acknowledgements The authors acknowledge Henrik Passmark at the National Board of Health and Welfare for compiling the data from the NPR and statisticians Bengt Bengtsson and Nils-Gunnar Pehrsson from Statistiska Konsultgruppen for statistical analysis.

Contributors $A B$ and JS contributed to the study design. $A B, P N, D F, O S$ and JS contributed to the interpretation and analysis of data. $A B$ wrote the first draft of the manuscript. PN, DF, OS and JS contributed to the final writing and revising of the manuscript and checked for important intellectual content. All authors approved of the final manuscript as submitted.

Funding This study was supported by financial grants from the Acta Otolaryngologica Foundation, the Freemason Child House Foundation in Stockholm and The Health and Medical Care Committee of the Regional Executive Board, Region Västra Götaland.

Competing interests None declared.

Ethics approval This study was approved by the regional ethical review board of Gothenburg, Sweden (Dnr 534-14).

Provenance and peer review Not commissioned; externally peer reviewed.

Data sharing statement No additional data are available.

Open Access This is an Open Access article distributed in accordance with the Creative Commons Attribution Non Commercial (CC BY-NC 4.0) license, which permits others to distribute, remix, adapt, build upon this work noncommercially, and license their derivative works on different terms, provided the original work is properly cited and the use is non-commercial. See: http:// creativecommons.org/licenses/by-nc/4.0/

\section{REFERENCES}

1. McNeill RA. A history of tonsillectomy: two millenia of trauma, haemorrhage and controversy. Ulster Med J 1960;29:59-63.

2. Cullen KA, Hall MJ, Golosinskiy A. Ambulatory surgery in the United States, 2006. National Health Statistics Report 2009;2:1-25.

3. Iber C, Ancoli-Israel S, Chesson AL Jr, et al. The AASM manual for the scoring of sleep and associated events. American Academy of Sleep Medicine, 2007.

4. Hultcrantz E, Ericsson E. Factors influencing the indication for tonsillectomy: a historical overview and current concepts. ORL J Otorhinolaryngol Relat Spec 2013;75:184-91.

5. Sarny S, Habermann W, Ossimitz G, et al. What lessons can be learned from the Austrian events? ORL J Otorhinolaryngol Relat Spec 2013;75:175-81.

6. Koltai PJ, Solares CA, Koempel JA, et al. Intracapsular tonsillar reduction (partial tonsillectomy): reviving a historical procedure for obstructive sleep disordered breathing in children. Otolaryngol Head Neck Surg 2003;129:532-8.

7. Hultcrantz E, Ericsson E. Pediatric tonsillotomy with the radiofrequency technique: less morbidity and pain. Laryngoscope 2004;114:871-7.

8. Windfuhr JP, Werner JA. Tonsillotomy: it's time to clarify the facts. Eur Arch Otorhinolaryngol 2013;270:2985-96.

9. Gysin C. Indications of pediatric tonsillectomy. ORL J Otorhinolaryngol Relat Spec 2013;75:193-202.

10. Parker NP, Walner DL. Trends in the indications for pediatric tonsillectomy or adenotonsillectomy. Int J Pediatr Otorhinolaryngol 2011;75:282-5.

11. Rosenfeld RM, Green RP. Tonsillectomy and adenoidectomy: changing trends. Ann Otol Rhinol Laryngol 1990;99(Pt 1):187-91.

12. Guilleminault $C$, Eldridge $F L$, Simmons $F B$, et al. Sleep apnea in eight children. Pediatrics 1976;58:23-30.
13. http://www.socialstyrelsen.se/register/halsodataregister/ patientregistret/inenglish

14. Ludvigsson JF, Andersson E, Ekbom A, et al. External review and validation of the Swedish national inpatient register. BMC Public Health 2011;11:450.

15. http://www.scb.se/en_/ (in English)

16. Vestergaard $\mathrm{H}$, Wohlfahrt $\mathrm{J}$, Westergaard $\mathrm{T}$, et al. Incidence of tonsillectomy in Denmark, 1980 to 2001. Pediatr Infect Dis J 2007;26:1117-21.

17. Koshy E, Bottle A, Murray J, et al. Changing indications and socio-demographic determinants of (adeno)tonsillectomy among children in England-are they linked? A retrospective analysis of hospital data. PLoS One 2014;9:e103600.

18. Van Den Akker EH, Hoes AW, Burton MJ, et al. Large international differences in (adeno)tonsillectomy rates. Clin Otolaryngol Allied Sci 2004;29:161-4.

19. de Jongh E, Opstelten W, Werkgroep NHG-Standaard Acute keelpijn. Revision of the Dutch College of General Practitioners practice guideline 'acute sore throat'. Ned Tijdschr Geneeskd 2015;159:A9456.

20. Lau AS, Upile NS, Wilkie MD, et al. The rising rate of admissions for tonsillitis and neck space abscesses in England, 1991-2011. Ann $R$ Coll Surg Engl 2014;96:307-10.

21. Boss EF, Marsteller JA, Simon AE. Outpatient tonsillectomy in children: demographic and geographic variation in the United States, 2006. J Pediatr 2012;160:814-19.

22. Friberg $\mathrm{D}$, Lundkvist $\mathrm{K}, \mathrm{Li} \mathrm{X}$, et al. Parental poverty and occupation as risk factors for pediatric sleep-disordered breathing. Sleep Med 2015;16:1169-75.

23. Factor $\mathrm{SH}$, Levine OS, Harrison $\mathrm{LH}$, et al. Risk factors for pediatric invasive group A streptococcal disease. Emerg Infect Dis 2005;11:1062-6.

24. Ward SL, Marcus CL. Obstructive sleep apnea in infants and young children. J Clin Neurophysiol 1996;13:198-207.

25. Lumeng JC, Chervin RD. Epidemiology of pediatric obstructive sleep apnea. Proc Am Thorac Soc 2008;5:242-52.

26. Erickson BK, Larson DR, St Sauver JL, et al. Changes in incidence and indications of tonsillectomy and adenotonsillectomy, 19702005. Otolaryngol Head Neck Surg 2009;140:894-901.

27. Mitchell RB, Pereira KD, Friedman NR. Sleep-disordered breathing in children: survey of current practice. Laryngoscope 2006;116:956-8.

28. Patel $\mathrm{HH}$, Straight $\mathrm{CE}$, Lehman EB, et al. Indications for tonsillectomy: a 10 year retrospective review. Int $J$ Pediatr Otorhinolaryngol 2014;78:2151-5.

29. Bhattacharyya N, Lin HW. Changes and consistencies in the epidemiology of pediatric adenotonsillar surgery, 1996-2006. Otolaryngol Head Neck Surg 2010;143:680-4.

30. Mårild S, Bondestam M, Bergström R, et al. Prevalence trends of obesity and overweight among 10 -year-old children in western Sweden and relationship with parental body mass index. Acta Paediatr 2004;93:1588-95.

31. Moraeus L, Lissner L, Sjöberg A. Stable prevalence of obesity in Swedish schoolchildren from 2008 to 2013 but widening socio-economic gap in girls. Acta Paediatr 2014;103:1277-84.

32. de Munter JS, Friedl A, Lind S, et al. Stability in the prevalence of Swedish children who were overweight or obese in 2003 and 2011. Acta Paediatr 2016;105:1173-80.

33. Hultcrantz E, Ericsson E, Hemlin C, et al. Paradigm shift in Sweden from tonsillectomy to tonsillotomy for children with upper airway obstructive symptoms due to tonsillar hypertrophy. Eur Arch Otorhinolaryngol 2013;270:2531-6.

34. Hultcrantz E, Hemlin C, Eggertsen R, et al. Indikation för tonsillotomi på barn och ungdomar 2011 (Swedish). http://www.skl.se/vi_ arbetar_med//halsaochvard/kvalitetsutveckling/medicinskaindikationer (accessed Jun 2012).

35. Acevedo JL, Shah RK, Brietzke SE. Systematic review of complications of tonsillotomy versus tonsillectomy. Otolaryngol Head Neck Surg 2012;146:871-9.

36. Ericsson E, Lundeborg I, Hultcrantz E. Child behavior and quality of life before and after tonsillotomy versus tonsillectomy. Int J Pediatr Otorhinolaryngol 2009;73:1254-62.

37. Odhagen E, Sunnergren $\mathrm{O}$, Hemlin $\mathrm{C}$, et al. Risk of reoperation after tonsillotomy versus tonsillectomy: a population-based cohort study. Eur Arch Otorhinolaryngol 2016;273:3263-8. 